\title{
Developing Curriculum For Introducing CyberSecurity To K-12 Students
}

\section{Mr. Brandon Gregory Morton, Drexel University (Eng.)}

Brandon Morton is currently pursuing a Ph.D. in Electrical Engineering at Drexel University. He received his B.S. in Computer Engineering from the University of Maryland, Baltimore County in 2009 and his M.S. in Electrical Engineering from Drexel University in 2011. He was an NSF GK-12 fellow from 2011 to 2014. Currently he is researching methods for detecting influence between musical artists.

\section{Prof. Youngmoo Kim, Drexel University Matthew Nester VanKouwenberg \\ Mr. Chris Lehmann, Science Leadership Academy}

Chris Lehmann is the founding principal of the Science Leadership Academy, a progressive science and technology high school in Philadelphia, PA. The Science Leadership Academy is an inquiry-driven, project-based, 1:1 laptop school that is considered to be one of the pioneers of the School 2.0 movement nationally and internationally. The school was recognized by Ladies Home Journal as one of the Ten Most Amazing Schools in the US, has been recognized as an Apple Distinguished School from 2009 through 2013 and has been written about in many publications including Edutopia Magazine, EdWeek and the Philadelphia Inquirer. In September 2013, Chris opened Science Leadership Academy @ Beeber campus, the second campus in the SLA model. Chris returned to his native Philadelphia after nine years as an English Teacher, Technology Coordinator, Girls Basketball Coach and Ultimate Frisbee coach at the Beacon School in New York City, one of the leading urban public schools for technology integration.

In June 2013, Chris was named Outstanding Leader of the Year by the International Society of Technology in Education. In November of 2012, Chris was named one of Dell's \#Inspire100 - one of the 100 people changing the world using Social Media. In April of 2012, Chris won the Lindback Award for Excellence in Principal Leadership in the School District of Philadelphia. In September of 2011, Chris was honored by the White House as a Champion of Change for his work in education reform. In June 2010, Chris was named as one of the "30 Most Influential People in EdTech" by Technology \& Learning Magazine. In 2009, Chris was a honoree for the Association of Supervision and Curriculum Development's Outstanding Young Educator Award. Chris was named as one of " 40 Under 40 by Philadelphia Business Journal in 2009. In 2006, the National School Board Association named Chris one of "20 to Watch" among American administrators. In 2001, Chris was honored by MOUSE as a Champion of Technology and Education for his work on building the portal at the Beacon School.

Chris has written for such education publications as Principal Leadership Magazine, Learning and Leading with Technology Magainze, and the School Library Journal. Chris has spoken at conferences all over the world, including TEDxPhilly, TEDxNYED, the National Association of Secondary Schools Conference, SXSW, the Building Learning Communities conference, the International Society of Technology in Education, the Philadelphia Area Educational Technology Conference, The Yahoo Cybercitizen Conference, the Innovative Learning Conference, The Council of Educational Facilities Planners Regional Conference, the K12-Online Conference, the International Conference on Technology and Education and at LinuxWorld, and he has worked with many schools and districts in the U.S. and England as a consultant. Chris received his B.A. in English Literature from the University of Pennsylvania and his M.A. in English Education from Teachers College, Columbia University. Chris is co-editor of What School Leaders Need to Know about Digital Technologies and Social Media, the author of the education blog this blog Practical Theory and is father to Jakob and Theo.

Jessica S Ward, Drexel University (Eng.) 


\section{Developing Curriculum For Introducing Cyber Security To K-12 Students}

\section{Introduction}

In the twenty-first century, the world has become heavily dependent on the Internet. Governments, financial institutions, and social media sites such as Facebook, which store large amounts of personal data, are constantly at risk of being attacked by hackers. Because of its importance, securing cyberspace has been selected by the National Academy of Engineers as an important challenge to address in the coming years. While most agree that securing the Internet is a critical issue, few understand what is involved in this task ${ }^{1}$. To increase awareness of this issue, we have developed a set of lessons for high school students that introduce the basic concepts needed to understand the task of securing cyberspace.

\section{Drexel NSF GK-12 Program}

The Drexel University NSF GK-12 Fellowship program (DGE-0947936) encourages K-12 students to pursue careers in STEM fields by using the fourteen National Academy of Engineering (NAE) Grand Challenges ${ }^{1}$ as motivational and instructional tools. The NSF-funded program pairs graduate students in STEM with K-12 teachers to develop project-based lessons that reinforce the Grand Challenge concepts in their science and math curricula. These projects attempt to connect the abstract and conceptual challenges with real world applications. In this process of demystifying technologies students take for granted, we hope to help them recognize that the concepts they are learning in science and math can lead to a better world.

For this particular set of activities, students will be mainly focusing on the Securing Cyberspace challenge, which involves engineering solutions for protecting the flow of electronic information over the Internet. This particular challenge was chosen due to the wide-ranging applications and potential real-world examples it offers to students.

\section{Science Leadership Academy}

This study was conducted at the Science Leadership Academy, a partnership school between the School District of Philadelphia and the Franklin Institute. Students from three mixed grade classes at this urban high school participated in a series of activities and inquiry-driven projects designed to help them learn fundamental science and engineering principles related to cyber security. Students were led through activities from a basic introduction to waves and signal processing to encryption and network security. Student learning was be assessed by evaluations given before and after the activities.

The project culminated in a radio transmitter design competition where some students built transmitters that sent encrypted messages while the other students attempted to jam, intercept, or otherwise interfere with these messages. This project was chosen since the networking and

\footnotetext{
${ }^{1}$ http://www.engineeringchallenges.org
} 
computational resources are limited at the school. We incorporated engineering, specifically basic ideas of signal processing so that the students could see one application of how cyber security and engineering are related.

Since the participating students were in mixed grade classes they all had different levels of prior knowledge, most of them not having encountered periodic functions before in an academic setting. Given this we chose the progression of activities to bring the students to fully engage with the material and learn specifics of cyber security and how it relates to engineering as well as general science, math and engineering skills.

\section{Activity Descriptions}

\section{Franklin Institute Visit}

Before we started the activities dealing with cyber security, we wanted students to realize the importance of cyber security and how it has been addressed in real-world applications. Taking advantage of the partnership the Science Leadership Academy has with The Franklin Institute, students were taken to see the exhibit, Spy: The Secret World of Espionage. This exhibit consisted of recently declassified C.I.A. artifacts and documents detailing the history of espionage in the United States. Students were asked to pay close attention to certain exhibits involving communications, securing data, and computers. For example, there was a voice alteration exhibit, where students could record short audio messages and perform different modulation and filtering techniques in an attempt to disguise their voice. Students were also shown an exhibit featuring live traffic camera feeds from different cities around the world, showing them how prevalent surveillance has become and why it's becoming more important to protect access to these streams of information. Once this visit was completed, we held a discussion about what they saw and how it related to the activities they would be performing.

\section{Password Guessing Activity}

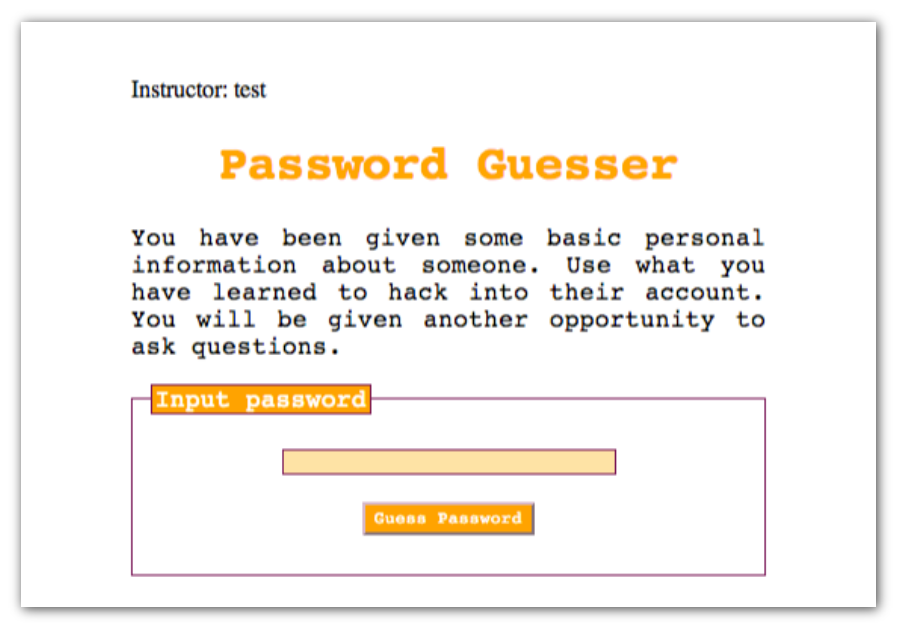

Figure 1: Screenshot of website used for password guessing activity.
One of the first activities we performed with the students is a password guessing activity. Students' most visible example of cyber security is the login screen of most websites, which include inputting a password. In addition to allowing the GK-12 fellow to introduce themselves, the activity introduced cyber security to students in a familiar context. Students were asked to guess a password using information given to them that simulated data easily found on a social media website. By the end of the activity students were expected to be able to explain the following terms: cyber security, brute-force attack, dictionary 
attack, and social engineering. They were also asked to examples of scenarios where cyber security is necessary.

To start the activity, instructors informed the students that they were going to try and guess a password based on information that would be given to them in a short introduction/speech. This speech simulated publicly available information on social networking websites and contained hints to the instructor's password in the form of hobbies, favorite things, and other typical publicly available information. For example, if the password contained a favorite football team, the introduction would mention that the teacher is interested in football.

The group of students were only allowed to ask five questions about the password. These questions were limitied to the content of the password (e.g., what's your favorite football team) and not the actual alphanumeric make up of the password (e.g., does the password have a number in it). Once they finished asking their questions, they were given 5-7 minutes to guess the password using a website developed for this activity ${ }^{2}$. If no student guessed the password in the 5-7 minutes, they were allowed to ask five more questions and then continue guessing. Once the password was guessed, a discussion was held about cyber security.

\section{Tuning Fork Activity}

In order to understand sound, waves, and many of the equations that characterize electronics, students must first understand periodicity. This was a fundamental step in learning cyber-security because it generated a kinesthetic appreciation for many of the equations, the language used in discussing cyber-security and strengthening cyber security. The vast majority of our students had not encountered periodic functions yet in their academic careers, so in order for the students to
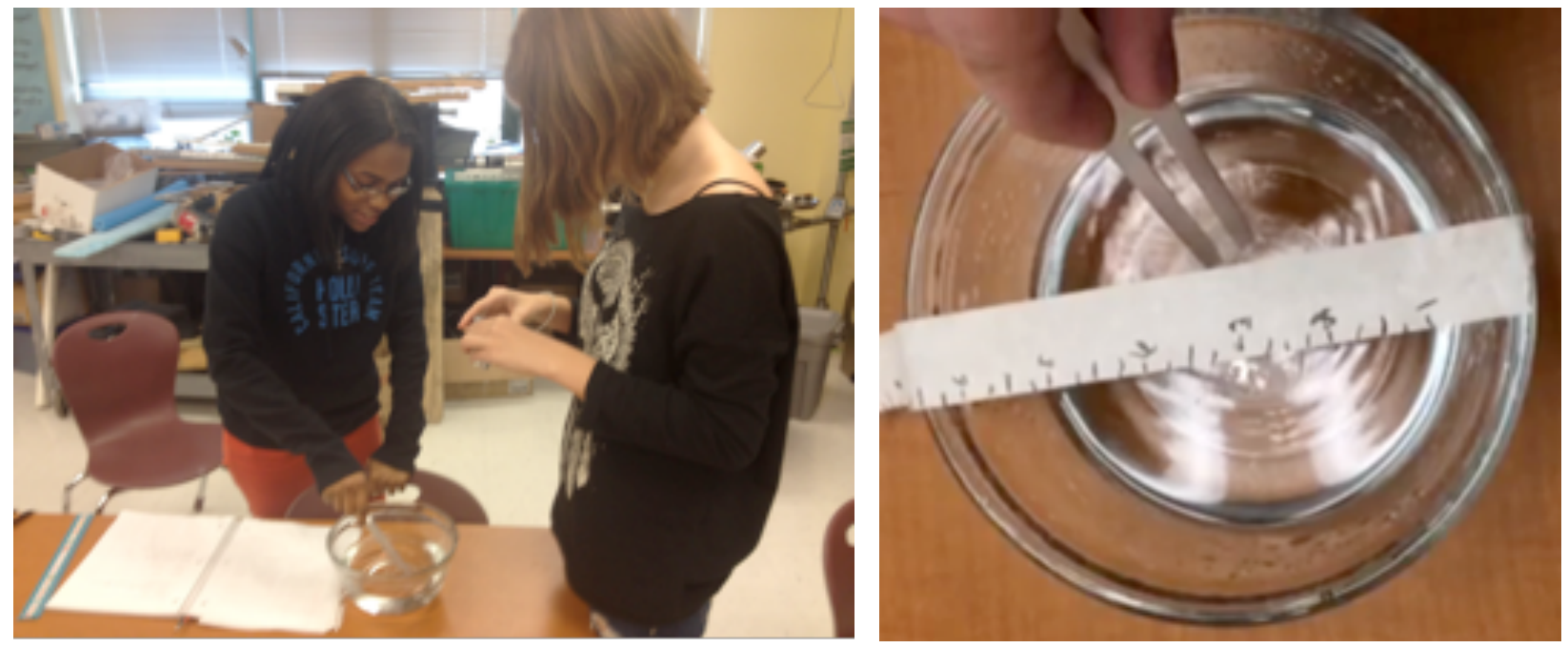

Figure 2: Images of the tuning fork activity. On the left are two students working on the tuning for task. On the right is one of the experimental setups designed by a student to measure the waves in the water. This image was captured from a video on a mobile phone.

${ }^{2}$ http://music.ece.drexel.edu/ bmorton/hackActivity 
understand basic waves and the formulas used to describe them, we had the students use tuning forks to visualize the waves. We also used this exercise to practice qualitative and quantitative observations and to help the students think about how to gather and record data. We designed an exercise that took approximately 5-10 minutes of demonstration and 30-40 minutes of student preparation and presentation.

In order to run this activity, we first set up a clear bowl of water with a light shining from underneath onto the ceiling and darken the room. Once the setup was complete, we dropped some spheres and irregularly shaped objects in the water one at a time having the students comment on what they observed in the projection on the ceiling. After this discussion, we submerged a vibrating tuning fork into the water and had the students observe the projection again and contrast the waves from the tuning fork with the waves from the non-vibrating objects.

After this, we split students into groups of two and three with their own bowls of water. They were given two or more tuning forks of different pitches and asked to make some qualitative observations about the waves produced when the forks were dipped into their bowls. After the students formed some ideas about the waves in the bowl, they were asked them to collect quantitative data to verify their qualitative assumptions. This part of the activity was explained in vague terms to the students leaving them with the task of finding a way to measure the distance between the waves in the bowl. During this time, instructors walked around from group to group prompting them with questions about what tools would help them quantify measurements useful for verifying the student's assumptions.

In our particular classroom, every group was using tape measures and timers and recording video and/or taking pictures with their cell phones within 10 minutes of the time they were given the task. They then used these measurements to see that the waves from the tuning forks had fixed distances that decayed at a steady rate and that the distances between the waves seemed to vary with the pitch; furthermore some students described a correlation that the decay varied with the initial decibels as measured by an audio program on a laptop.

Students were then asked to put together small mini-presentations to work on their communication skills such as how to display data and the analysis of their observations.

\section{Pendulum Activity}

Once the students started to get an understanding of periodicity, we wanted to bring them to a point where they were comfortable with the equations they would see and encounter, so we introduced the pendulum activity as a multi-day activity which was used to provide more information on the concepts of frequency and amplitude as well as formalize the language used through equations. Although we had a specific purpose in mind for this activity, it could also be expanded to introduce harmonic motion, sine waves, parametric equations, and also the concept of a carrier wave. This exercise could also be used to help with many other skills such as representation of data in various types of figures, recognizing the differences between independent, dependent, and controlled variables, designing an experiment, controlling an experiment, differentiating between quantitative and qualitative data, data analysis and trend 
lines, presentation skills and many more. If desired, the module can be shortened based on desired outcomes.
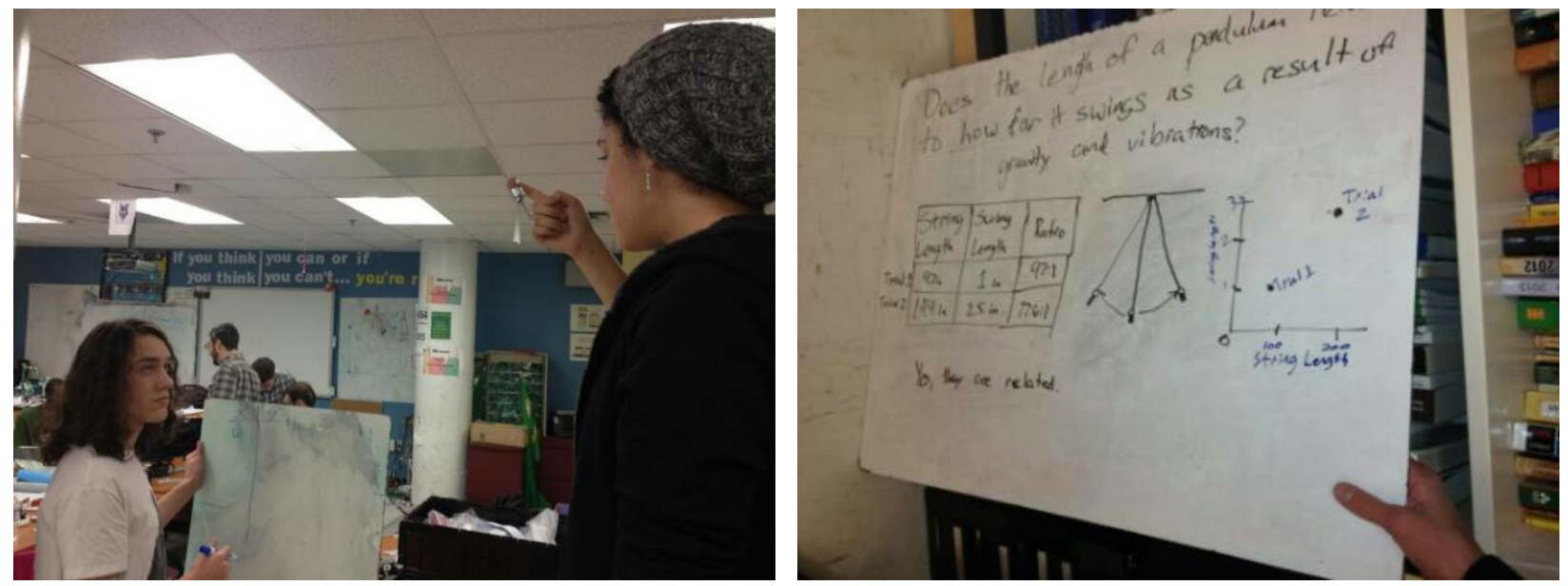

Figure 3: On the left is an image of students performing their experiment during the pendulum activity. On the right is their presentation.

For this activity, a discussion was held, defining a pendulum as a mass suspended from a fixed point that gets its energy from gravity. Students were then given some string, eyebolts, a nut, and some washers with the instructions to use these materials to learn about the motion of the pendulum. As with the Tuning Fork activity, the instructions were left vague, inviting the students to come up with their own hypothesis about the motion of a pendulum. After 5 minutes, students were asked to give a short presentation on their findings. They were then directed to design an experiment and collect data to verify or disprove one of their hypothesis. Once they collected their data, students created presentations on small whiteboards to present to the class consisting of their question, a data chart, a graph of their data, and their conclusion. This sequence of designing and presenting has the potential for multiple iterations depending on the academic level of the students and the amount of guidance they are given for their presentations. In previous lessons dealing with presenting data, we saw that some students might try to use a style of graph that is inappropriate, and this activity provided an opportunity to address this issue. Also students often struggled with isolating a control variable for their experiment (e.g., the angle from which the pendulum is released). If this occurs instructors can choose to either tell

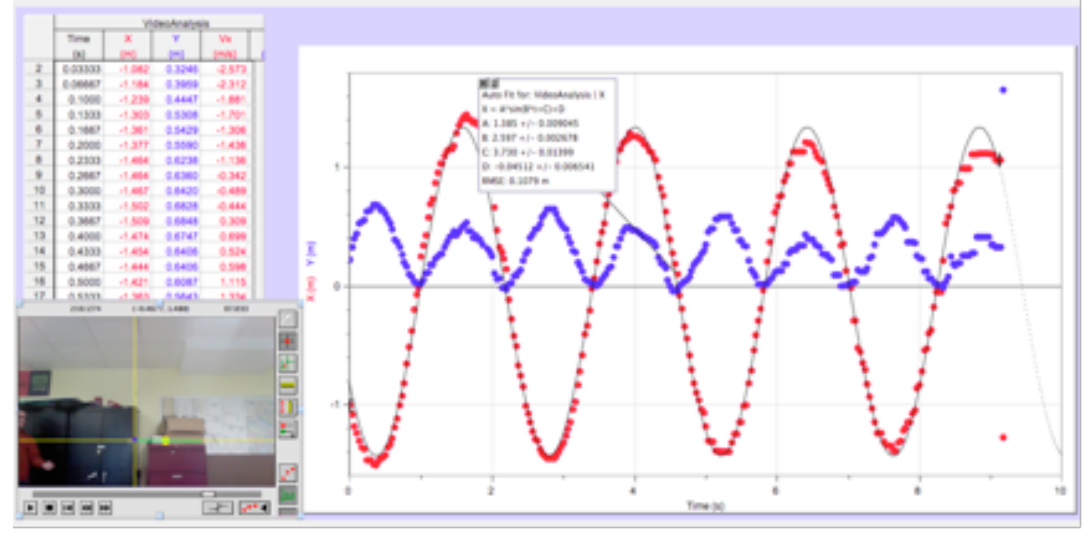

Figure 4: Above is a screenshot of the LoggerPro plotting. them how to control the experiment or let them see inconsistencies with their data and iteratively improve the experiment. This is the stage where you can either spend the time to get a deep understanding of the nuances, or move quickly and have the students memorize the content with a mild kinesthetic understanding. 
After the students had a controlled experiment and demonstrated repeatable data, they inserted videos of their pendulum into the LoggerPro (or the free LoggerLite) software. Using this software, students were able to indicate the position of the pendulum mass (eyebolt and washers) for each frame of the video. The software then provided the $\mathrm{x}$ and $\mathrm{y}$ coordinates along with the time of each point. Students plotted these coordinates as a function of time, which allowed for discussion of parametric equations, which became useful when we introduced different modulation techniques for the eventual radio project.

This activity is easily adaptable to align with instructor's expectations of what their students' performance level and familiarity with this subject. For instance, you can tell the students which variables to modify, how to fix the pivot point, or give them a template for their presentations.

\section{Sound Wave Activity}

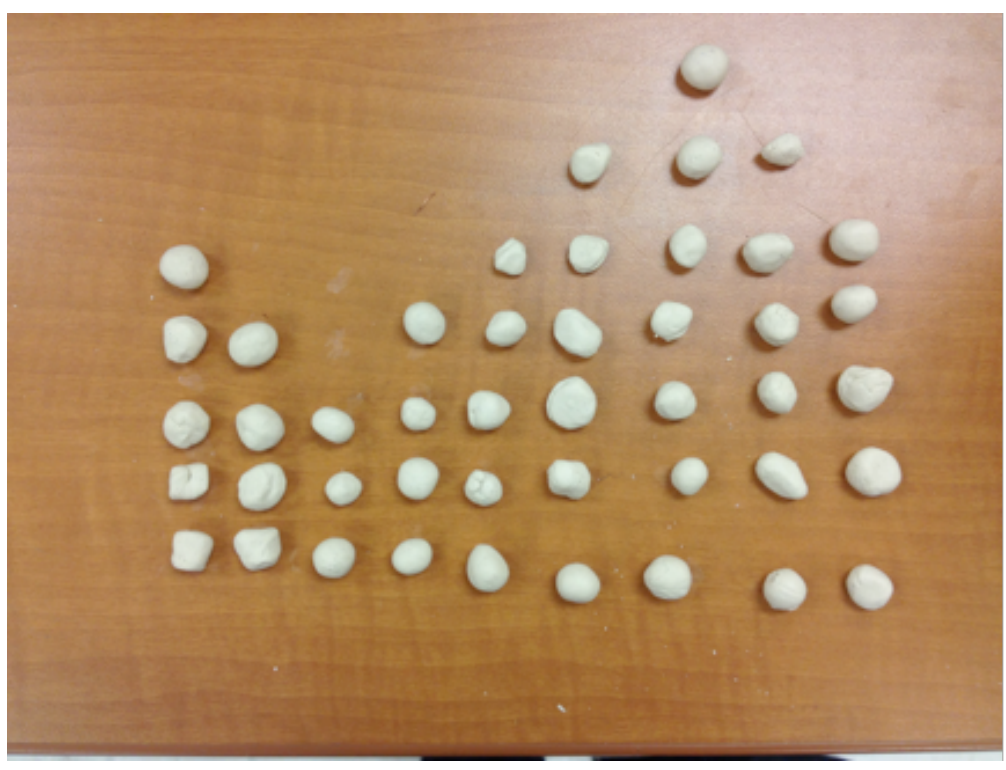

Figure 5: Picture of the clay used in the sound wave activity.
During the tuning fork and pendulum exercises, many of the students were using vocabulary usually associated with waves, such as frequency and amplitude, but did not have a good grasp of what those words actually meant. We decided to spend some time explaining those terms using sound waves. Most of our students came into class knowing the words "sound wave," but had no idea of what they actually were, or even worse had the misconception that the particles of air actually move up and down as a wave. To address this issue, we created a shorter module inspired by an exercise created by Clair

DeChant's presentation to the STEM school in Egypt, wherein the students created representations of sound waves using clay.

First students were lead in a brief discussion about waves. Specifically, we looked at Dr. D. Russell's acoustics animation ${ }^{3}$. This animation shows a simulation of the behavior of air molecules when acted on by a speaker cone. Students were shown the entire animation to see an example of how the molecules interact and then asked to focus on a smaller given area where they make observations about the density of the air particles in this area. To further enforce the concepts of frequency and amplitude, students were shown a PowerPoint animation similar to the original animation, but simplified by removing a large number of the molecules shown. As the instructor, stepped through each frame of the PowerPoint animation, students were asked to

${ }^{3}$ http://www.acs.psu.edu/drussell/Demos/StandingWaves/StandingWaves.html 
place clay clumps representing particles, with time on the horizontal and number of particles on the vertical axis. An example can be seen in Figure 3.

After this, a brief discussion was held to ensure that everyone has an understanding of the terms 'amplitude' and 'frequency'. Students were asked to demonstrate this knowledge by asking them to transform the graphs given different criteria, such as a change in volume, which is associated with amplitude, or a change in pitch, which is related to frequency.

\section{RSA Algorithm Activity}

In this activity, one of the most commonly used algorithms for encryption was presented to the students. The RSA algorithm uses large prime numbers to encrypt information and is based on the idea that it is difficult to factor a large number into two prime numbers. Students were first shown a presentation where they were guided through an example of encrypting information using the algorithm. The steps involved in this are shown below and more details can be found online ${ }^{4}$.

1. Find two prime numbers $\mathrm{p}$ and $\mathrm{q}$.

2. Calculate $\mathrm{n}=\mathrm{pq}$.

3. Calculate $\mathrm{z}=(\mathrm{p}-1)(\mathrm{q}-1)$.

4. Choose a value $\mathrm{k}$, which is a prime number chosen to be $3<\mathrm{k}<\mathrm{z}$. (k and $\mathrm{n}$ become your public key).

5. Choose a value $\mathrm{d}$, such that $\mathrm{k} \cdot \mathrm{d}=1 \bmod \phi(\mathrm{n})$.

They were then asked to perform the encryption with a partner and send a simple message to each other. As an added goal, students were then given the opportunity to try and crack an RSA encryption set up by the instructors to get an idea of the difficulty of this task.

\section{Speaker Building Activity}

In the Speaker Building activity [2, 3], students constructed speakers using widely available materials. A detailed description of this activity can be found in a previous paper [4]. Before beginning construction, a brief introduction to the principle of electromagnetic induction and the components and construction of speakers was given to the students. Students then wrapped their own voice coils and constructed their own speaker housings. This activity allowed the students to demonstrate that they could apply much of the knowledge gained over the previous activities as well as introduce transduction, which is useful in trying to understand the culminating project.

To make the voice coils, students wrapped magnetically insulated wire around a paper cylinder. Students were given the option to use a plate, cup or bowl as their speaker cone; the voice coil was attached to this item. Using more index cards, the speaker cone/voice coil assembly was suspended onto another plate, bowl, or cup. Once construction was complete, an amplified signal from a volunteer's mp3 player was applied to the coil using a $75 \mathrm{~W}$ off-the-shelf home stereo

\footnotetext{
${ }^{4}$ http://doctrina.org/How-RSA-Works-With-Examples.html
} 
amplifier. Time permitting, the students were allowed to experiment with different numbers of turns in their speaker coils and different types of speaker cone and mount materials to make qualitative assessments of how these changes affect the fidelity of the sound.
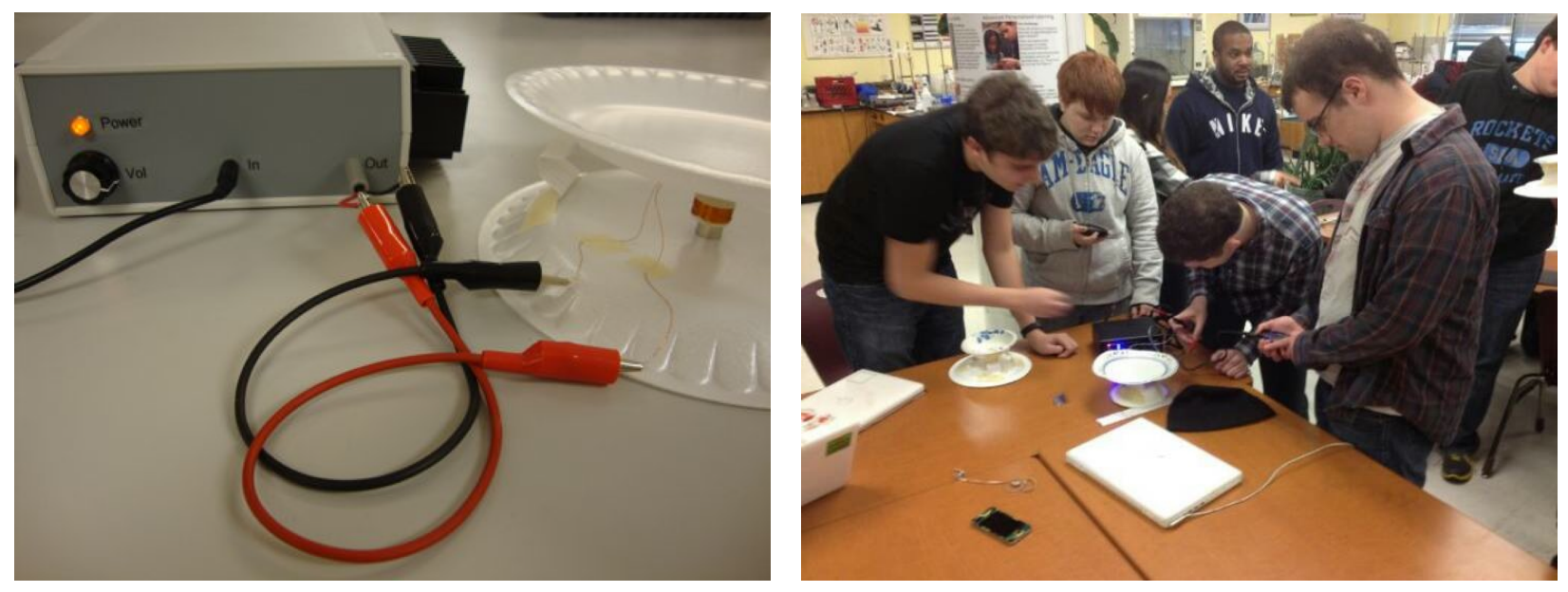

Figure 6: Speaker building activity. The left figure shows a finished speaker. On the right a group of students is testing their speaker.

\section{Evaluation Results}

To evaluate the efficacy of our activities, we asked the students to take an evaluation before the activities and then a final evaluation after completing them. The lessons were deployed from September to December of 2014 by a GK-12 fellow and an SLA teacher. The evaluations and lessons were administered in two engineering classrooms consisting of 37 students ranging from

\begin{tabular}{|cc|}
\hline \multicolumn{2}{|c|}{ Table 1: Results of Evaluations (out of 52 points) } \\
\hline Pre-Activity Average Evaluation Score & Post-Activity Average Evaluation Score \\
9.95 & 19.81 \\
\hline
\end{tabular}

9th -12th grade. Both evaluations are given in Appendix A.

Shown in Table 1, it can be seen that the students show significant improvement after being led through the activities. Each question's post-activity average score increases from the pre-activity evaluation. The largest improvement was seen in question 13. Question 13 asks What are some engineering solutions to cyber security? The lowest increase is seen in question 8 , which asks the students to define amplitude modulation. On average each question's score increased by 0.77 points or by about $19 \%$. In Table 2, the aggregate results to both evaluations are given. You can see that the score on the post-activity average evaluations are twice as high as the pre-activity evaluations. 


\begin{tabular}{|r|c|c|}
\hline \multicolumn{2}{|c|}{ Table 2: Results of Evaluation Questions (out of 4 points) } \\
\hline & Pre-Activity Evaluation Average & Post-Activity Evaluation Average \\
\hline Q1 & 0.43 & 0.95 \\
\hline Q2 & 0.32 & 0.95 \\
\hline Q3 & 0.51 & 1.18 \\
\hline Q4 & 0.19 & 0.92 \\
\hline Q5 & 1.41 & 2.16 \\
\hline Q6 & 1.46 & 2.68 \\
\hline Q7 & 0.22 & 0.92 \\
\hline Q8 & 0.27 & 0.78 \\
\hline Q9 & 2.00 & 2.11 \\
\hline Q10 & 0.00 & 0.76 \\
\hline Q11 & 1.32 & 2.16 \\
\hline Q12 & 1.00 & 2.19 \\
\hline Q13 & 0.81 & 2.24 \\
\hline
\end{tabular}

\section{Conclusions}

We can see that our lessons and activities do have an affect on how students perform in an evaluation of their skills. These activities seem to be conveying the concepts necessary for any future cyber security activities we wish to perform. While the scores on the post-activity evaluation do show significant growth, they also show the need for modification of some of our approaches to teaching certain topics, especially basic wave phenomena.

\section{Acknowledgements}

This work is supported by NSF Awards DGE-0947936, IIS-0644151, and the Graduate Research Fellowship.

\section{Bibliography}

1. S. C. Douglas, "The INFINITY Project: Digital Signal Processing and Digital Music in High School Engineering Education," in IEEE Workshop on the Applications of Signal Processing to Audio and Acoustics, New Paltz, NY, 2001.

2. A. M. Batula, B. G. Morton, R. Migneco, M. Prockup, E. M. Schmidt, D. K. Grunberg, Y. E. Kim and A. K. Fontecchio, "Music Technology as an Introduction to STEM" in Proceedings of the 2012 ASEE Annual Conference, June 2012.

3. Y. E. Kim, A. M. Batula, R. Migneco, P. Richardson, B. Dolhansky, D. Grunberg, B. G. Morton, M. Prockup, E. M. Schmidt, and J. Scott, "Teaching STEM Concepts Through Music Technology and DSP," in Proceedings of the 14th IEEE Digital Signal Processing Workshop and 6th IEEE Signal Processing Education Workshop, 2011.

4. J. Gregorio, B. G. Morton, and Y. E. Kim, "Music Technology as a Vehicle to STEM / STEAM for High School Students," in ASEE Annual Conference, 2013. 


\section{Appendix A}

Pre-Activity Evaluation

1. Write binary number 0001010 in base 10 notation.

2. Write the base ten number 48 in binary notation.

3. What is a brute-forced attack on a password?

4. What is a dictionary attack on a password?

5. What is the prime factorization of the number 72 ?

6. What is the prime factorization of the number 44 ?

7. What is frequency modulation?

8. What is amplitude modulation?

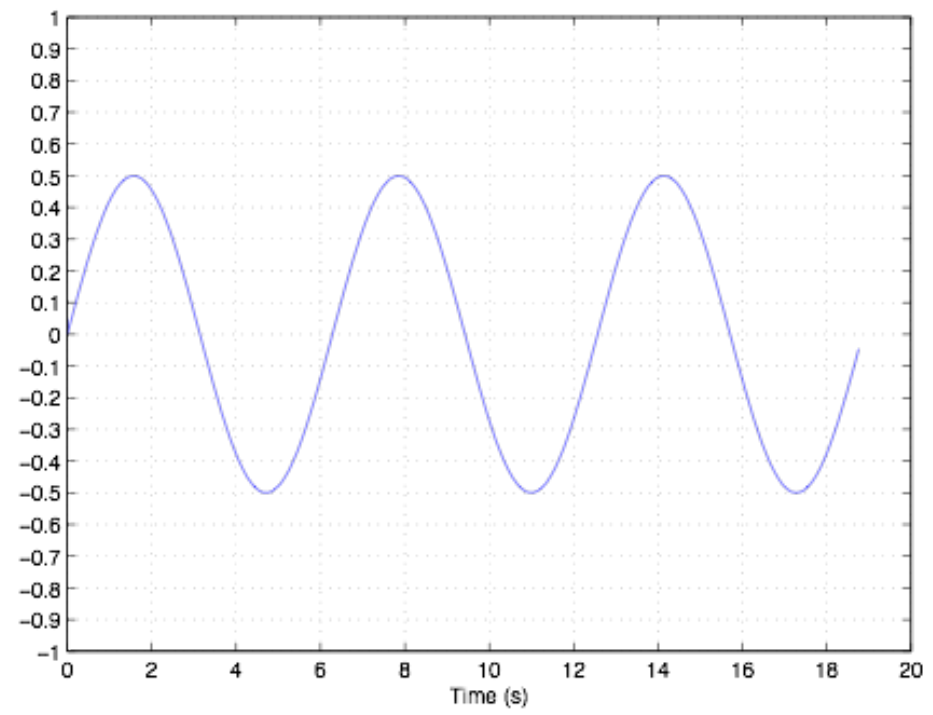

9. Using the graph above, what is the amplitude of this wave?

10. Using the graph above, what is the frequency of this wave?

11. What is cyber security?

12. Why is securing cyberspace important?

13. What are some engineering solutions to cyber security? 


\section{Post-Activity Evaluation}

1. Write binary number 1000111 in base 10 notation.

2. Write the base ten number 35 in binary notation.

3. What is a brute-forced attack on a password

4. What is a dictionary attack on a password

5. What is the prime factorization of the number 108 ?

6. What is the prime factorization of the number 47 ?

7. What is frequency modulation?

8. What is amplitude modulation?

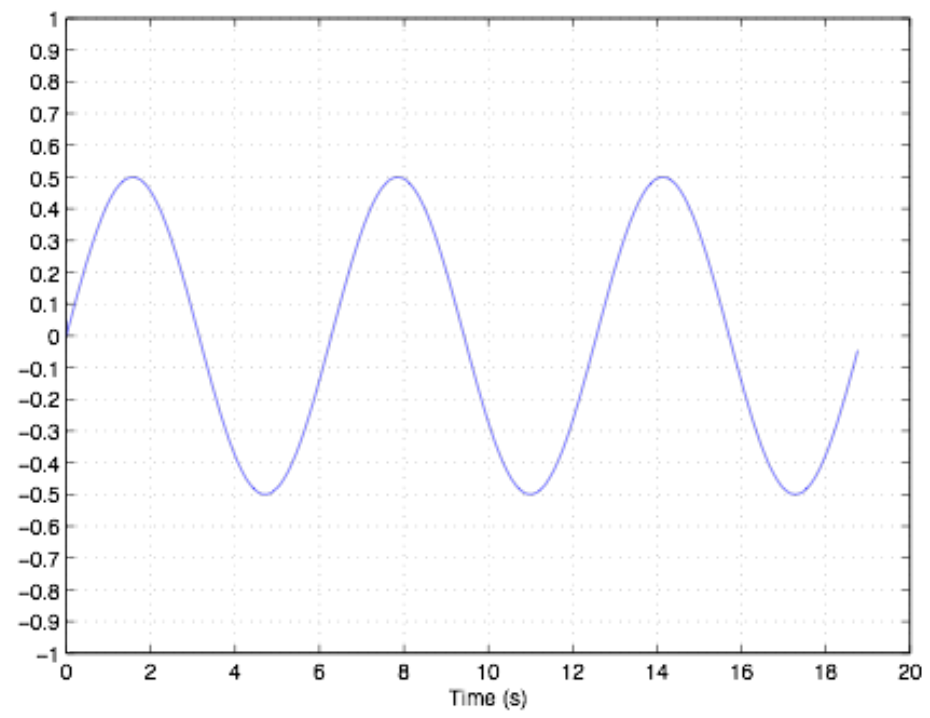

9. Using the graph above, What is the amplitude of this wave?

10. Given the graph above, What is the frequency of this wave?

11. What is cyber security?

12. Why is securing cyberspace important?

13. What are some engineering solutions to cyber security? 